Additional services for Parasitology:

Email alerts: $\underline{\text { Click here }}$

Subscriptions: $\underline{\text { Click here }}$

Commercial reprints: Click here

Terms of use : Click here

\title{
Detection of Leishmania lipophosphoglycan binding proteins in the gut of the sandfly vector
}

\author{
R. J. DILLON and R. P. LANE
}

Parasitology / Volume 118 / Issue 01 / January 1999, pp 27 - 32

DOI: null, Published online: 08 September 2000

Link to this article: http://journals.cambridge.org/abstract S0031182098003588

How to cite this article:

R. J. DILLON and R. P. LANE (1999). Detection of Leishmania lipophosphoglycan binding proteins in the gut of the sandfly vector. Parasitology, 118, pp 27-32

Request Permissions : $\underline{\text { Click here }}$ 


\title{
Detection of Leishmania lipophosphoglycan binding proteins in the gut of the sandfly vector
}

\author{
R. J. DILLON ${ }^{1 *}$ and R. P. LANE \\ ${ }^{1}$ Department of Biology and Biochemistry, University of Bath, Claverton Down, Bath BA2 $7 A Y$ \\ ${ }^{2}$ The Wellcome Trust, 183 Euston Rd, London NW1 2BE
}

(Received 23 Fune 1998; revised 14 Fuly 1998; accepted 14 Fuly 1998)

SUMMARY

Binding to the midgut microvillar surface in the sandfly Phlebotomus papatasi is a prerequisite for successful development of Leishmania major within the gut of the vector. This paper describes a method for detecting microvillar-associated proteins which act as ligands for the parasite surface glycoconjugate lipophosphoglycan (LPG). Adhesion of LPG to midgut proteins was visualized by probing midgut extracts with LPG using a Western ligand blotting technique. Procyclic L. major LPG bound to a microvillar polypeptide band of $65 \mathrm{kDa}$ (estimated in the non-reduced state) and bound variably to several lower molecular weight bands, probably degradation products or subunits of the primary binding polypeptides. Specificity of binding was confirmed by co-incubating biotinylated LPG with an LPG-specific mAb which resulted in a great reduction in binding.

Key words: Leishmania major, lipophosphoglycan, Phlebotomus papatasi, microvilli, midgut.

\section{INTRODUCTION}

Lipophosphoglycan (LPG) is the major surface molecule found on Leishmania promastigotes during their development in the gut of the sandfly vector. The LPG consists of a series of phosphorylated saccharide repeats linked to a lipid anchor via a carbohydrate core (Turco \& Descoteaux, 1992). The molecule undergoes structural changes in the saccharide repeats associated with development from the log phase (procyclic) to the metacyclic, mammalian infective form, of the promastigote (McConville et al. 1992). Both forms of LPG are expressed during development of the Leishmania major promastigote in the natural vector, Phlebotomus papatasi (Davies et al. 1990; Lang et al. 1991).

LPG is critical to the parasite's survival; strains of parasite lacking the intact surface coat fail to develop beyond the stage of bloodmeal digestion at which meal remnants are excreted (Pimenta et al. 1994). Two potential roles have been described for the LPG coat; protection against the hydrolytic proteases associated with bloodmeal digestion (Borovsky \& Schlein, 1987) and binding of the parasite to the midgut wall thus preventing ejection from the gut with the digested bloodmeal (Sacks et al. 1994).

L. major infections do modulate sandfly protease activities (Borovsky \& Schlein, 1987; Dillon \&

* Corresponding author: Department of Biology and Biochemistry, University of Bath, Claverton Down, Bath BA2 7AY. Tel: +01225826826 ext4292. Fax: +01225 826779. E-mail: R.J.Dillon@bath.ac.uk
Lane, $1993 a$ ) but there is no evidence of direct inhibition of protease by LPG and an LPG-defective strain remained viable in the presence of purified sandfly protease (Dillon \& Lane, unpublished observations). This does not, however, discount the possibility that LPG is indirectly inhibiting proteases or other hydrolases.

In vitro, attachment of the logarithmic, procyclic $L$. major promastigote to the midgut of $P$. papatasi is mediated via the terminally exposed galactose residues of the LPG (Pimenta et al. 1992). Thus parasites escaping from the digested bloodmeal, as the peritrophic matrix breaks down, attach to the microvillar surface of the midgut. Nothing is known of these binding sites. Subsequently the terminal saccharide residues are modified during metacyclogenesis so that the metacyclic form of the LPG binds less causing the parasite to be released from the surface and enabling its migration to the anterior part of the gut prior to transmission to the mammalian host. Interspecific differences in the terminal saccharides of the LPG could account, at least in part, for the specificity Leishmania species show to different sandfly species (Pimenta et al. 1994; Sacks et al. 1995; Butcher et al. 1996).

The purpose of this study was to detect adhesion molecules in the sandfly midgut to which parasites attach via LPG. Previous electron microscope studies revealed that the promastigotes bind to the microvillar membrane via the flagella-associated LPG (Lang et al. 1991; Saraiva et al. 1995). Therefore, instead of using crude midgut extracts, midgut microvillar (MV) proteins were selectively enriched (compared to other membrane and cyto- 
plasmic proteins) for use in Western ligand blots using calcium ion precipitation and differential centrifugation (Ferreira \& Terra, 1980). Binding was visualized by probing the blots with LPG.

\section{MATERIALS AND METHODS}

\section{Enrichment of microvillar proteins}

Initial extracts were prepared (Ferreira \& Terra, 1980; Houk, Arcus \& Hardy, 1986) using 50 midguts from 3 to 4-day-old female $P$. papatasi (colony originated from the Jordan Valley, Israel and reared according to the method described by Dillon \& Lane, $1993 a$ ). The midguts were ground in an icecold $200 \mu \mathrm{l}$ vol. glass homogenizer with isolation buffer (300 mM mannitol, $100 \mathrm{~mm}$ Tris $-\mathrm{HCl}$, $\mathrm{pH} 7 \cdot 2, \quad 1 \mathrm{~mm}$ phenylmethanesulfonyl fluoride (PMSF)) and made up to a final volume of $500 \mu \mathrm{l}$ of isolation buffer with $10 \mathrm{~mm} \mathrm{CaCl}{ }_{2}$. After incubation on ice for $15 \mathrm{~min}$ the suspension was centrifuged at $6000 \mathrm{~g}$ for $15 \mathrm{~min}$ at $4{ }^{\circ} \mathrm{C}$. The pellet was resuspended in fresh isolation buffer with $\mathrm{CaCl}_{2}$ and treated as above. The 2 supernatants were combined and centrifuged for $30 \mathrm{~min}$ at $19000 \mathrm{~g}$, the resulting pellet was used as the MV extract.

Aminopeptidase activities and protein determinations were performed as previously described (Dillon \& Lane, 1993a).

\section{Preparation of $L P G$}

Leishmania major LV39 (MRHO/SU/59/P-strain, originally from Rhombomys opimus, Uzbekistan; Scott \& Sher, 1986) was cultured from stocks of amastigotes stored in liquid nitrogen. Log phase promastigote cultures $\left(4 \times 10^{6} / \mathrm{ml}\right)$ were grown at $26{ }^{\circ} \mathrm{C}$ using $\alpha$-MEM medium supplemented with foetal calf serum (Kar et al. 1990). The LPG was purified from log phase promastigotes using octylSepharose (Pharmacia Biotech, Herts, UK) (McConville et al. 1987). Fractions containing LPG were determined by probing dot blots using the $\mathrm{mAb}$ CA7AE (CedarLane Labs, Ontario, Canada) which recognizes L. major LPG (Tolson et al. 1989). The quantity of $\mathrm{LPG}$ (stored at $-70^{\circ} \mathrm{C}$ ) is given as the dry weight of material obtained after freeze drying the appropriate fractions.

LPG was prepared for biotinylation by incubation in ice with $10 \mathrm{~mm}$ sodium periodate in acetate buffer, $\mathrm{pH} 5 \cdot 5$. The solution was ultrafiltered at $4{ }^{\circ} \mathrm{C}$ using a $10 \mathrm{kDa}$ cut-off filter (Centricon 10, Amicon, UK), retentate was resuspended in buffer and refiltered 3 times. Biotin hydrazide (Pierce, UK) was mixed with the retentate to a final dilution of $4 \mathrm{~mm}$ and incubated for $1 \mathrm{~h}$ at $20^{\circ} \mathrm{C}$. The suspension was ultrafiltered 3 times as described above with $10 \mathrm{~mm}$ phosphate buffer ( $\mathrm{pH} 7 \cdot 2)$ as the washing buffer. The efficacy of LPG biotinylation was checked by Western blot of LPG and biotinylated LPG.

\section{Western ligand blot with LPG}

MV extracts were prepared for gel electrophoresis by suspension in sample buffer, containing $1 \mathrm{mM}$ PMSF without reducing agent, and heating for $20 \mathrm{sec}$ at $95{ }^{\circ} \mathrm{C}$. Unless stated otherwise, $5 \mu$ l samples $(0 \cdot 2 \mu \mathrm{g}$ protein, equivalent to $\mathrm{MV}$ extract from 5 midguts) were loaded per lane and separated on 4-20\% SDS-polyacrylamide mini gels. The separated samples were transferred onto nitrocellulose membrane $(0.45 \mu \mathrm{m})$ using a semi-dry blotter (Multiphor Novablot, Pharmacia Biotech) with a constant current of $42 \mathrm{~mA}$ for $1-1.5 \mathrm{~h}$. The membrane was blocked overnight at $4{ }^{\circ} \mathrm{C}$ with $3 \%$ crystalline bovine serum albumin (BSA), 0.01\% Tween 20 and $150 \mathrm{~mm} \mathrm{NaCl}$ in $100 \mathrm{~mm}$ Tris- $\mathrm{HCl}$, pH 7.5. Lanes selected for total polypeptide detection were blocked overnight in $0.1 \%$ Tween 20 and $150 \mathrm{~mm} \mathrm{NaCl}$ in $100 \mathrm{~mm}$ Tris- $\mathrm{HCl}, \mathrm{pH} 7 \cdot 5$ (TTBS) and stained using Protogold with silver enhancement (British Biocell, Cardiff, UK).

To detect binding the nitrocellulose strips were incubated for $3 \mathrm{~h}$ with a solution of LPG extract $(6 \mu \mathrm{g} / \mathrm{ml})$ in $3 \%$ crystalline BSA, and $150 \mathrm{~mm} \mathrm{NaCl}$ in $50 \mathrm{~mm}$ Tris- $\mathrm{HCl}, \mathrm{pH} 7 \cdot 5$ and washed for $30 \mathrm{~min}$ with 4 changes of TTBS. Blots were probed with anti-LPG mAb CA7AE or WIC79.3. Probing with CA7AE was for $1 \mathrm{~h}$ at a dilution of $1: 2000$ in TTBS, the blot was washed with TTBS for $30 \mathrm{~min}$ (4 changes) and incubated with 1:1000 alkaline phosphatase-conjugated secondary antibody goat anti-mouse IgM (Calbiochem-Novabiochem, San Diego) with $3 \%$ normal goat serum in Tris-buffered saline (TBS). Other blots were incubated with WIC79.3 (De Ibarra, Howard \& Snary, 1982) using $1: 20$ diluted hybridoma culture supernatant, washed and incubated with 1:4000 alkaline phosphataseconjugated secondary antibody anti-mouse IgG (Southern Biotechnology, Alabama). After a final $30 \mathrm{~min}$ wash in TTBS (4 changes), blots were developed with nitroblue tetrazolium/BCIP (5bromo-4-chloro-3-indolyl phosphate) substrate (Vector Labs, UK).

\section{Western ligand blot with biotin-LPG}

Blots were prepared and blocked overnight as described above. Nitrocellulose strips were incubated for $3 \mathrm{~h}$ with $1: 1000$ dilution of biotin-LPG in a solution of $3 \%$ crystalline BSA, $0.01 \%$ Tween 20 and $150 \mathrm{~mm} \mathrm{NaCl}$ in $100 \mathrm{~mm}$ Tris-HCl, pH 7.5. After washing in TTBS for $30 \mathrm{~min}$ the strips were incubated with 1:1000 streptavidin alkaline phosphatase (Vector Labs) in the $3 \%$ BSA-buffered blocking solution for $45 \mathrm{~min}$, washed for $1.5 \mathrm{~h}$ in TTBS and developed with the substrate described above. 
RESULTS AND DISCUSSION

The total polypeptide profile for the blotted, nonreduced midgut microvillar extract from $P$. papatasi (Fig. 1, lane 6, Fig. 2, lane 1) revealed multiple bands including 2 major bands (121 and 85-87 kDa) and at least 9 other bands ranging from 19 to approximately $210 \mathrm{kDa}$. In comparison, reduced preparations of MV revealed major bands at $84-87 \mathrm{kDa}$ (data not shown). Coomassie blue stained SDS-PAGE gels of female mosquito (Culex tarsalis) MV extracts revealed 2 major bands with approximately 100 and $70 \mathrm{kDa}$ (Houk et al. 1986) under reducing conditions.

The method of calcium precipitation combined with differential centrifugation resulted in a $5 \cdot 3$-fold enrichment in MV proteins. Enrichment was estimated by comparing specific activities of the microvillar marker aminopeptidase (Terra \& Ferreira, $1994)$ in the crude extracts $(3 \cdot 0 \pm 0 \cdot 2 \mu \mathrm{M} / \mu \mathrm{g}$ protein) with activity in the microvillar extract $(16.0 \pm 1 \cdot 5 \mu \mathrm{M} / \mu \mathrm{g}$ protein). The method takes advantage of the highly charged nature of the MV membrane compared to other gut cell membranes (Ferreira \& Terra, 1980). Although this process results in the loss of some MV protein, it greatly reduces contamination with irrelevant proteins associated, for example, with the basolateral membrane and thus enabled loading of a greater quantity of the proteins normally exposed to developing parasites.

Procyclic LPG from L. major consistently bound to 3-4 bands in Western ligand blots prepared from MV extracts of 6 different midgut preparations. Preliminary experiments established that increased LPG binding was obtained using non-reduced, in comparison to reduced, samples for SDS-PAGE probably because reduction of disulphide bridges generally results in the loss of ligand binding (Hossenlopp \& Binoux, 1994). Overnight blocking was used to promote renaturation of the proteins.

The LPG binding was visualized initially with the anti-LPG IgM mAb CA7AE which recognizes the repeated phosphorylated galactose $\beta$-1,4-mannose disaccharide unit of Leishmania sp. LPG (Tolson et al. 1989). The LPG bound to proteins of 121, 86 and $65 \mathrm{kDa}$ (estimated in the non-reduced state; Fig. 1, arrowed bands, lane 3). The amount of binding correlated with a reduction in the amount of microvillar extract loaded; 3 bands are clearly visible in lane 3 but are barely visible in lane 5 where the amount of protein loaded was one sixth of that loaded in lane 3. Control lanes consisted of membrane strips not incubated with mAb or LPG. There was a small amount of apparent cross-reactivity of the mAb towards the gut polypeptides with the 121 and $86 \mathrm{kDa}$ bands (faint bands in lane 1).

Other blots were prepared and the LPG detected using WIC 79.3, an IgG mAb specific for the LPG of L. major (Handman, Greenblatt \& Goding, 1984). Binding of the ligand was detected with 121, 86 and $65 \mathrm{kDa}$ but also with 34 and $29 \mathrm{kDa}$ (arrowed on Fig. 2 , lane 5) and some faint bands of lower molecular weight. The amount of binding was also correlated with amount of protein loaded per lane as noted in the previous experiment. The absence of any visible bands in lane 3 shows that the amount of protein loaded was below the threshold of protein required to detect LPG binding.

Comparison of the main LPG blot (Fig. 2, lane 5) with those of the major polypeptide bands (lane 1) reveals a specific binding process which is not associated with the abundance of individual polypeptide bands; the $65 \mathrm{kDa}$ LPG binding peptide gave the strongest signal but migrated just below a major $70 \mathrm{kDa}$ band.

To verify the results obtained with mAbs a biotin label was used as a more direct method of ligand binding detection. The biotin-streptavidin method not only removed any possibility of Ab crossreactivity with midgut proteins but also gave a stronger signal. Biotin labelled and unlabelled LPG was detected using the $\mathrm{CA} 7 \mathrm{AE} \mathrm{mAb}$ to reveal a broad band characteristic of the glycoconjugate LPG (Fig. 3A). Incubation of microvillar blots with biotin-LPG (Fig. 3B) revealed binding to over 6 bands including the $64 \mathrm{kDa}$ band previously detected with $\mathrm{mAbs} / \mathrm{LPG}$. Binding was strongest with lower molecular weight bands particularly a $19 \mathrm{kDa}$ band. Some of the lower molecular weight LPG binding proteins might be degradation products, or subunits of the larger primary binding proteins. This might explain some of the variability in the number of bands detected with LPG binding activity. Another possibility is that a combination of specific and nonspecific binding occurred, particularly with the bands which migrated at 121 and $86 \mathrm{kDa}$. However, substituting the wash post-LPG incubation with a high salt wash $(650 \mathrm{~mm} \mathrm{NaCl}$ in Tris- $\mathrm{HCl} \mathrm{pH} 7 \cdot 5$ with Tween 20) to remove non-specific binding did not reduce LPG binding (data not shown).

The most conclusive evidence for specific LPG binding to midgut polypeptides is given (Fig. 3B, lane 3) where incubation of biotin-LPG with CA7AE (1:50) resulted in abolition of binding to both the $64 \mathrm{kDa}$ band and the lower molecular weight bands. With the techniques available it was not possible to determine if the bands contained 1 or several proteins. Therefore we cannot conclude that there is only a single binding protein on the sandfly midgut.

However, there is no reason to expect that the parasite binds to only one or two specific receptors in the midgut. Indeed, it would be in the interests of the parasite to bind to a molecule that was both common in the gut as well as functionally important to the sandfly. Even the specific attachment to the macrophage by the Leishmania promastigote is 


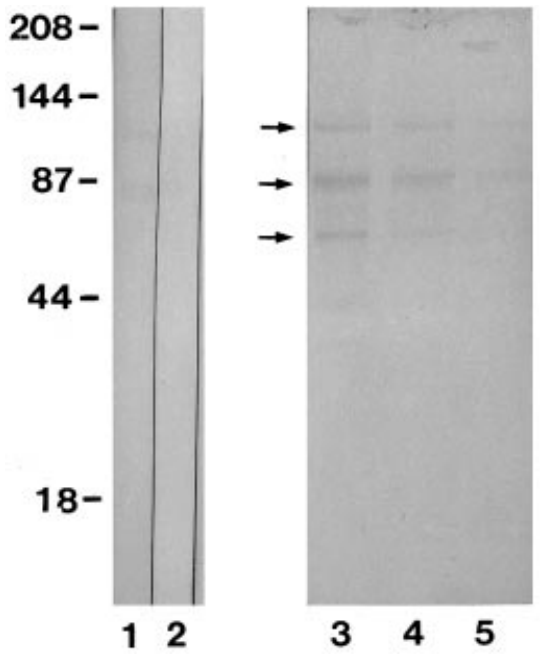

Fig. 1. Western ligand blot analysis of lipophosphoglycan-binding proteins in microvillar extracts from the midgut of Phlebotomus papatasi. Proteins separated under non-reducing SDS-PAGE were electroblotted and incubated with procyclic LPG from Leishmania major. LPG binding was detected using CA7AE anti-LPG specific mAb. SDS-PAGE 4-20\% gradient gel. Molecular weight standards are given in $\mathrm{kDa}$. Arrows denote the main LPG binding locations on the nitrocellulose membrane strips. Lane 1, $10 \mu \mathrm{l}$ of extract/lane, control, no LPG. Lane 2, $10 \mu \mathrm{l}$ of extract, control, no mAb. Lanes 3-5, LPG incubated with a strip containing decreasing quantities of microvillar extract per lane; $24 \mu 1$ (lane 3), $12 \mu 1$ (lane 4), $4 \mu \mathrm{l}$ (lane 5). Lane $6,5 \mu \mathrm{l}$ of extract. Protein stained for microvillar extract.

thought to be mediated by binding to a variety of receptors (see e.g. Green et al. 1994). Perhaps the microvillar surface glycoproteins exposed to the luminal environment have developed common structural configurations which enable them to resist the hydrolytic mileau and consequently LPG is binding to a site common to several different proteins. Biotinylated T. brucei also binds many proteins from midgut homogenates derived from the tsetse gut (van den Abbeele et al. 1996). Another possibility is that the LPG also binds to some cytoskeletal elements associated with the microvillal extract in addition to cell surface molecules. Leishmania promastigotes will attach to collagen for example (Lira, Rosales-Encina \& Arguello, 1997). However, attempts to remove the cytoskeletal elements from the microvillar membranes using hyperosmotic Tris (Jordão, Terra \& Ferreira, 1995) are impractical in the present context because it would require prodigious quantities of insects.

Several studies have sought to identify lectins in the sandfly midgut using a strategy of in vitro agglutination of promastigotes with whole midgut extracts and inhibition by selected sugars (Wallbanks, Ingram \& Molyneux, 1986; Volf \& Killick-Kendrick, 1996; Svobodova, Volf \& KillickKendrick, 1996; Palanova \& Volf, 1997). The studies
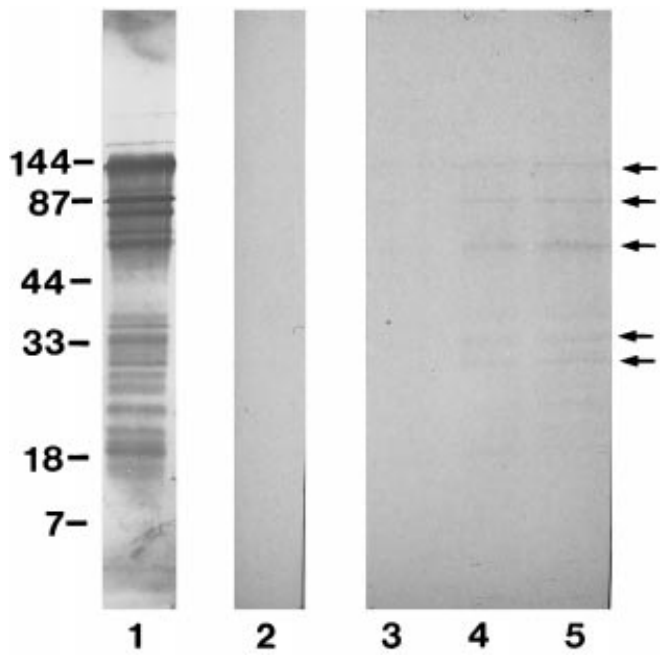

Fig. 2. Western ligand blot analysis of lipophosphoglycan-binding proteins in microvillar extracts from the midgut of Phlebotomus papatasi. LPG binding was detected using WIC79.3, anti-Leishmania major LPG specific mAb. SDS-PAGE $12 \%$ gel.

Molecular weight standards are given in $\mathrm{kDa}$. Arrows denote the main LPG binding locations on the nitrocellulose membrane. Lane 1, $5 \mu \mathrm{l}$ of extract. Protein stained for microvillar extract. Lane 2, $12 \mu \mathrm{l}$ of extract, control, no LPG. Lanes 3-5, LPG incubated with a strip containing increasing quantities of microvillar extract per lane; $4 \mu \mathrm{l}$ (lane 3), $12 \mu \mathrm{l}$ (lane 4), $24 \mu \mathrm{l}$ (lane $5)$.
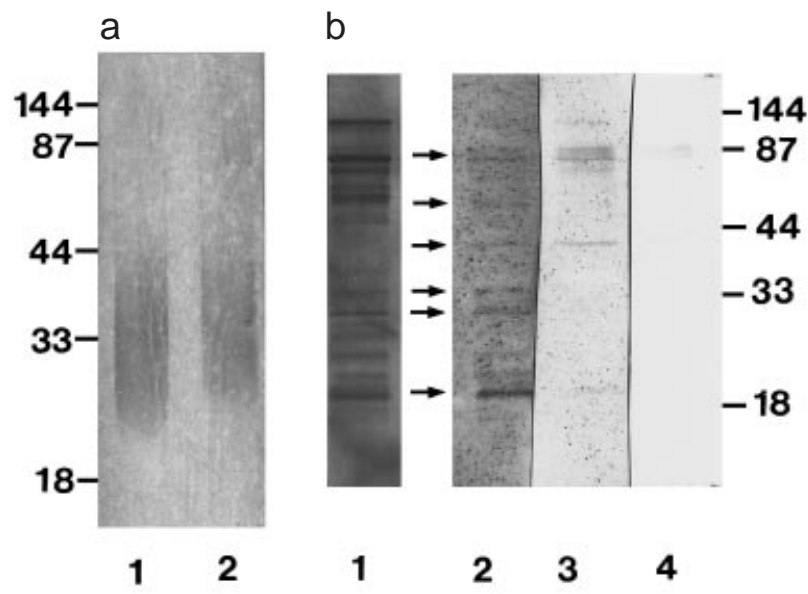

Fig. 3. Western ligand blot analysis of lipophosphoglycan-binding proteins in microvillar extracts from the midgut of Phlebotomus papatasi. SDS-PAGE $12 \%$ gel. Biotinylated LPG used with streptavidin. Molecular weight standards are given in $\mathrm{kDa}$. Arrows denote the main LPG binding locations on the nitrocellulose membrane. (A) Blot of LPG (lane 1) and biotinylated LPG (lane 2) detected with anti-LPG mAb CA7AE. (B) Lane 1, $5 \mu 1$ of extract. Protein stained for microvillar extract. Lane 2, blot incubated with biotin-LPG. Lane 3, blot incubated with biotin-LPG and CA7AE. Lane 4, no biotin-LPG control. 
suggest that haemagglutination activity, located throughout the body (Palanova \& Volf, 1997), is greatest in the midgut lumen during bloodmeal digestion (Volf \& Killick-Kendrick, 1996) and is almost entirely lost after defaecation. It is clear that these lectin-like compounds cannot be involved in the specific binding of the Leishmania parasite to the microvilli.

Information on the biochemical structure of insect microvilli and the associated carbohydrate-rich glycocalyx is limited (Lane, Dallai \& Ashhurst, 1996). However, it is known that the dominant integral proteins on the MV membrane of Dipteran insects are hydrolases involved in the terminal processes of digestion (Jordão et al. 1995). In Dipteran sandflies there are highly active $\alpha$ glucosidases (Dillon \& El Kordy, 1997) and the MV preparations are enriched more than 8 -fold for $\alpha$ glucosidase activity (Dillon \& El Kordy, unpublished observations). One possibility is that LPG sugars are binding to glycosidases. Other hydrolases, $100-120 \mathrm{kDa}$ glycoprotein aminopeptidases, have been identified as the MV receptor for the endotoxins of the insect pathogen Bacillus thuringiensis in Lepidoptera (Knight, Crickmore \& Ellar, 1994; Valaitis et al. 1997). Aminopeptidase is present on the MV membrane in sandflies before and after bloodfeeding (Dillon \& Lane, $1993 b$ ) and is another potential binding protein.

This investigation received financial support from the Wellcome Trust. We are grateful to Professor R. Sinden and Dr P. Billingsley for the use of laboratory facilities at Imperial College, London. We also acknowledge Professor M. A. J. Ferguson for helpful suggestions. We thank Ms P. Aiyenuro and Ms Z. Adams for excellent support in providing the sandflies and parasites.

\section{REFERENCES}

ABbeele, J. VAN DEN, DRIEssche, E. VAN, ClaEs, Y., LE RAY, D. \& COOSEmans, M. (1996). Trypanosome binding proteins of the tsetse flies Glossina palpalis gambiense and G. morsitans morsitans. International Fournal for Parasitology 26, 113-116.

BOROVSKY, D. \& SCHLEIN, Y. (1987). Trypsin and chymotrypsin-like enzymes of the sandfly Phlebotomus papatasi infected with Leishmania and their possible role in vector competence. Medical and Veterinary Entomology 1, 235-242.

Butcher, B. A., TUrco, s. J., hilty, B. A., Pimenta, P. F., PANUNZIO, M. \& SACKS, D. L. (1996). Deficiency in $\beta-1,3$,-galactosyltransferase of Leishmania major lipophosphoglycan mutant adversely influences the Leishmania sandfly interaction. Fournal of Biological Chemistry 271, 20573-20579.

DAVies, C. R., COOPER, A. M., PEACOCK, C., LANE, R. P. \& BLACKWELL, J. M. (1990). Expression of LPG and GP63 by different developmental stages of Leishmania major in the sandfly Phlebotomus papatasi. Parasitology 101, 337-343.

DE IBARRA, A. A., HOWARD, J. D. \& SNARY, D. (1982).
Monoclonal antibodies to L. tropica major: specificities and antigen location. Parasitology $\mathbf{8 5}$, 523-531.

DILlON, R. J. \& EL KORDY, E. (1997). Carbohydrate digestion in sandflies: $\alpha$-glucosidase activity in the midgut of Phlebotomus langeroni. Comparative Biochemistry and Physiology 116 B, 35-40.

DILlON, R. J. \& LANE, R. P. (1993a). Influence of Leishmania infection on bloodmeal digestion in the midguts of Phlebotomus papatasi and P. langeroni. Parasitology Research 79, 492-496.

DILlON, R. J. \& LANE, R. P. (1993b). Blood meal digestion in the midguts of Phlebotomus papatasi and Phlebotomus langeroni. Medical and Veterinary Entomology 7, 225-232.

FERREIRA, C. \& TERRA, W. R. (1980). Intracellular distribution of hydrolases in midgut caeca cells from an insect with emphasis on plasma membrane bound enzymes. Comprehensive Biochemistry and Physiology 66B, 467-473.

GREen, P. J., FEIZI, T., STOLl, M. S., THEIL, S., PRESCOTt, A. \& McCONVille, M. J. (1994). Recognition of the major cell surface glycoconjugates of Leishmania parasites by the human serum mannan-binding protein. Molecular and Biochemical Parasitology 66, 319-328.

handman, E., GREenblatt, C. L. \& GODing, J. W. (1984). An amphipathic sulphated glycoconjugate of Leishmania: characterisation with monoclonal antibodies. EMBO Fournal 3, 2301-2306.

HOSSENLOPP, P. \& BINOUX, M. (1994). Use of peptide ligands for the detection of binding proteins by Western blotting. In Protein Blotting. A Practical Approach (ed. Dunbar, B. S.), pp. 169-188. IRL Press, Oxford.

HOUK, E. J., ARCUS, Y. M. \& HARDY, J. L. (1986). Isolation and characterization of brush border fragments from mosquito mesenterons. Archives of Insect Biochemistry and Physiology 3, 135-146.

JORDÃO, B., TERRA, W. R. \& FERREIRA, C. (1995). Chemical determinations in microvillar membranes purified from brush borders isolated from the larval midgut of one Coleoptera and two Diptera species. Insect Biochemistry and Molecular Biology 25, 417-426.

KAR, K., MUKERJI, K., NASKaR, K., BHATTACHARYA, A. \& GHOSH, D. K. (1990). Leishmania donovani: a chemically defined medium suitable for cultivation and cloning of promastigotes and transformation of amastigotes to promastigotes. Fournal of Protozoology 37, 277-279.

KNight, P. J. K., CRICKMORE, N. \& ElLAR, D. (1994). The receptor for Bacillus thuringiensis CryIA(c) deltaendotoxin in the brush border membrane of the lepidopteran Manduca sexta is aminopeptidase N. Molecular Microbiology 11, 429-436.

LANE, N. J., DALlai, R. \& ASHHURST, D. E. (1996). Structural macromolecules of the cell membranes and the extracellular matrices of the insect midgut. In Biology of the Insect Midgut (ed. Lehane, M. J. \& Billingsley, P. F.), pp. 115-150. Chapman \& Hall, London.

LANG, T., WARburg, A., SACKS, D., CROFT, S., LANE, R. \& BlaCKWELL, J. M. (1991). Transmission and scanning 
EM-immunogold labelling of Leishmania major lipophosphoglycan in the sandfly Phlebotomus papatasi. European Fournal of Cell Biology 55, 362-372.

LIRA, R., ROSALES-ENCINA, J. L. \& ARGUELlo, C. (1997). Leishmania mexicana: Binding of promastigotes to type 1 collagen. Experimental Parasitology 85, 149-157.

McCONVILLE, M. J., BACiC, A., MitChell, G. F. \& HANDMAN, E. (1987). Lipophosphoglycan of Leishmania major that vaccinates against cutaneous leishmaniasis contains an alkylglycerophosphoinositol lipid anchor. Proceedings of the National Academy of Sciences, USA 84, 8941-8945.

McCONVIlle, M. J., TURCO, S. J., FERGUSON, M. A. J. \& SACKS, D. L. (1992). Developmental modification of lipophosphoglycan during the differentiation of Leishmania major promastigotes to an infectious stage. EMBO Fournal 11, 3593-3600.

PALANOVA, L. \& VOLF, P. (1997). Carbohydrate binding specificities and physico-chemical properties of lectins in various tissues of phlebotomine sandflies. Folia Parasitologica 44, 71-76.

Pimenta, P. F. P., SARAiva, E. M. B., ROWTON, E., MODi, G. B., Garraway, L. A., Beverley, S. M., TURCO, S. J. \& SACKS, D. L. (1994). Evidence that the vectorial competence of phlebotomine sandflies for different species of Leishmania is controlled by structural polymorphisms in the surface lipophosphoglycan. Proceedings of the National Academy of Sciences, USA 91, 9155-9159.

Pimenta, P. F., TURCO, S. J., McCONVIlle, M. J., LAWYer, P. G., PERKINS, P. V. \& SACKS, D. L. (1992). Stagespecific adhesion of Leishmania promastigotes to the sandfly midgut. Science 256, 1812-1815.

SACKS, D. L., SARAIVA, E. M., ROWTON, E., TURCO, S. J. \& PIMENTA, P. F. (1994). The role of the lipophosphoglycan of Leishmania in vector competence. Parasitology 108 (Suppl.) S55-S62.

SACKS, D. L., Pimenta, P. F. P., McCONVille, M. J., SCHNEIDER, P. \& TURCO, S. J. (1995). Stage-specific binding of Leishmania donovani to the sand fly vector midgut is regulated by conformational changes in the abundant surface lipophosphoglycan. Fournal of Experimental Medicine 181, 685-697.

SARAiva, E. M. B., PIMENTA, P. F. P., BRODIN, T. N., ROWTON, E., MODi, G. B. \& SACKs, D. L. (1995). Changes in lipophosphoglycan and gene expression associated with the development of Leishmania major in Phlebotomus papatasi. Parasitology 111, 275-287.

SCOTT, P. \& SHER, A. (1987). A spectrum in the susceptibility of leishmanial strains to intracellular killing by murine macrophages. Fournal of Immunology 136, 1461-1466.

SVOBodova, M., VOLF, P. \& KILLICK-KENDRICK, R. (1996). Agglutination of Leishmania promastigotes by midgut lectins from various species of phlebotomine sandflies. Annals of Tropical Medicine and Parasitology 90, 329-336.

TERRA, W. R. \& FERREIRA, C. (1994). Insect digestive enzymes: properties, compartmentalization and function. Comparative Biochemistry and Physiology 109B, 1-62.

TOLSON, D. L., TURCO, S. J., BEECROFT, R. P. \& PEARSON, T. W. (1989). The immunochemical structure and surface arrangement of Leishmania donovani lipophosphoglycan determined using monoclonal antibodies. Molecular and Biochemical Parasitology 35, 109-118.

turco, s. J. \& Descoteaux, A. (1992). The lipophosphoglycan of Leishmania parasites. Annual Review of Microbiology 46, 65-94.

valaitis, A. P., Mazza, A., Broussaeu, R. \& Masson, L. (1997). Interaction analyses of Bacillus thuringiensis Cry1A toxins with two aminopeptidases from gypsy moth midgut brush border membranes. Insect Biochemistry and Molecular Biology 27, 529-539.

VOLF, P. \& KILLICK-KENDRICK, R. (1996). Postengorgement dynamics of haemagglutination activity in the midgut of phlebotomine sandflies. Medical and Veterinary Entomology 10, 247-250.

WALLBANKS, K. R., INGRAM, G. A. \& MOLYNEUX, D. H. (1986). The agglutination of erythrocytes and Leishmania parasites by sandfly gut extracts: evidence for lectin activity. Tropical and Medical Parasitology 37, 409-413. 